\section{An Experimental Study on Ultrasonic Machining of Pure Titanium Using Designed Experiments}

In the present research work, the effect of several process parameters on the machining characteristics of pure titanium (ASTM Grade-I) has been reported. The machining characteristics that are being investigated are tool wear rate and the quality of the machined surface in terms of the surface finish. The mechanism of material removal was has also been correlated with the machining conditions. Four different process parameters were undertaken for this study; Tool material, abrasive material, grit size of the slurry used and power rating of the machine. The optimal settings of parameters are determined through experiments planned, conducted and analyzed using Taguchi method. The significant parameters are also identified and their effect on tool wear rate and surface roughness is studied. The results obtained have been validated by conducting the confirmation experiments.

Keywords: titanium, ultrasonic drilling, tool wear rate, surface roughness, optimization

\section{Introduction}

Titanium and its alloys are alternative for many engineering applications due to their superior properties such as chemical inertness, high strength and stiffness at elevated temperatures, high strength to weight ratio, corrosion resistance, and oxidation resistance. However these properties also make titanium and its alloys difficult to shape and machine into a precise size and shape. As a result, their widespread applications have been hindered by the high cost of machining with current technology (Thoe and Aspinwall, 1998; Benedict, 1987). The machining characteristics for titanium and its alloys using conventional machining processes are summarized below (Hong and Makus, 2001):

- Titanium and its alloys are poor thermal conductors. As a result, the heat generated when machining titanium cannot dissipate quickly; rather, most of the heat is concentrated on the cutting edge and tool face. About $50 \%$ of the heat generated is absorbed by into the tool while machining titanium alloy (Ti6Al-4V) (Takeyama and Murata, 1962).

- During machining, titanium alloys exhibit thermal plastic instability that leads to unique characteristics of chip formation. The shear strains in the chip are not uniform; rather, they are localized in a narrow band that forms serrated chips.

- The contact length between the chip and the tool is extremely short (less than one-third the contact length of steel with the same feed rate and depth of cut). This implies that the high cutting temperature and the high stress are simultaneously concentrated near the cutting edge (within $0.5 \mathrm{~mm}$ ).

- Serrated chips create fluctuations in the cutting force; this situation is further promoted when alpha-beta alloys are machined. The vibrational force, together with the high temperature, exerts a micro-fatigue loading on the cutting tool, which is believed to be partially responsible for severe flank wear (Hartung and Kramer, 1982).

- $\quad$ The surface finish achieved by a single machining process (no finishing operations) is poor.

Therefore, there is a crucial need for reliable and cost-effective machining processes for titanium and its alloys. Over the last few decades, there have been great advancements in the development of cutting tools, including coated carbides, ceramics, cubic boron nitride and polycrystalline diamond. These have found applications

Paper accepted May, 2008. Technical Editor: Anselmo Eduardo Diniz. in the machining of cast iron, steels and high temperature alloys such as nickel based alloys and super alloys. However, none of these newer developments in cutting tool materials have had successful application in improving the machinability of titanium alloys (Ezugwu and Wang, 1997). Most cryogenic machining studies on titanium and its alloys have documented improved machinability when freezing the workpiece or cooling the tool using a cryogenic coolant. However, inherent weaknesses exist in these approaches (Hong and Makus, 2001).

Although the basic machining properties of titanium metal cannot be altered significantly, their effects can be greatly minimized by decreasing temperatures generated at the tool face and cutting edge. Economical production techniques have been developed through use of low cutting speeds, maintaining high feed rates, using generous amounts of cutting fluid and using sharp tools and replacing them at the first sign of wear (ASM international, 1988).

Machining recommendations, such as noted above, may require modification to fit particular circumstances in a given shop. For example, cost, storage, or requirements may make it impractical to accommodate a very large number of different cutting fluids. Savings achieved by making a change in cutting fluid may be offset by the cost of changing fluids. Likewise, it may be uneconomical to inventory cutting tools which may have only infrequent use. Also, the design of parts may limit the rate of metal removal in order to minimize distortion (of thin flanges, for example) and to corner without excessive inertia effects (Wood and Favor, 1972).

Nontraditional machining processes such as electric discharge machining and laser beam machining have been applied to the machining of titanium and its alloys in recent times, but even these processes have their own limitations; the most prominent are the surface finish and dimensional inaccuracies besides their undesirable effects on the machined surface such as heat affected zone, recast layer and thermal stresses (Kremer et al., 1981). These adverse effects can lower the working life of the components critically. Loss of fatigue strength and hence surface integrity is another problematic area in machining of titanium. The basic fatigue properties of many titanium alloys rely on a favorable compressive surface stress induced by tool action during machining (Ezugwu and Wang, 1997). Ultrasonic Machining (USM) could be another alternative machining process that can be applied commercially to the machining of titanium; as this process is known to be free from all these adverse effects on the machined component, and the repeated impacts of abrasive grains on the work surface lead to a favorable compressive surface stress thereby improving the fatigue life of titanium components along with the surface integrity. 
However, there is critical lack of evidence for the application of USM for machining of titanium in the literature available till now. Hence, in the present investigation, ultrasonic drilling has been explored as an alternative machining method for pure titanium (ASTM Grade-I). The machining characteristics that are to be investigated are tool wear rate and quality of machined surface in terms of surface roughness of the machined surface.

Studying the effects of experimental parameters requires many experiments, much time and some certain statistical techniques for quantitative evaluation of the effects. Various design-of-experiments (DOE) methods are widely used to reduce this problem. DOE methods set up the efficient experimental schedule and produce a statistical analysis to indicate quickly and easily what parameters are important for the final results. In particular, the Taguchi method is one of the most powerful DOE methods for experiments. The advantages of using the Taguchi method are that many more factors can be optimized simultaneously and quantitative information can be extracted by only a few experimental trials. Therefore, this method has been extensively applied in industry (Bandell and Disney, 1989).

The machining performance of ultrasonic machining has been investigated by a few researchers using DOE techniques. Jadoun et al (2006) investigated the tool wear rate in ultrasonic drilling of engineering ceramics. The effect of four important process variables-tool material, grit size, power rating and slurry concentration on TWR was computed using Taguchi's L-27 OA. It was concluded that all of these input variables significantly affect the TWR in ultrasonic drilling. Two way interactions between toolgrit size and tool-power rating were also found to be significant. Optimum results for TWR were obtained with tungsten carbide as tool material, with a power rating of $200 \mathrm{~W}$ and a fine grit size of 500. Aspinwall and Kasuga (2001) have reported the use of a coarser abrasive, high static force and hollow tool with a higher power rating level to obtain optimum material removal rate (MRR) and tool wear rate in ultrasonic machining of titanium aluminide. The thickness of strain hardened layer was found to be of the order of 30-50 microns. An investigation on rotary ultrasonic machining of ceramic matrix composites has been reported using three variable two level full factorial design (Lee et al., 2005). Three input variables (spindle speed, feed rate and ultrasonic power) were considered for estimating MRR and cutting force under different experimental conditions. It was found that all the three input variables affect the MRR significantly. However, for cutting force as response, only spindle speed was found to be significant.

It is evident from the literature review that no effort has been made to investigate ultrasonic drilling process particularly for machining of titanium using this approach. Thus, the main thrust of this investigation is the parametric optimization with regard to tool wear rate and surface quality in USM process.

\section{Nomenclature}

$$
\begin{aligned}
\mu & =\text { mean of the population } \\
D F & =\text { degrees of freedom } \\
\% P & =\text { percent contribution } \\
S S & =\text { sum of squares } \\
M S & =\text { mean error square } \\
\mathrm{CI} & =\text { confidence Interval } \\
M R R & =\text { material removal rate } \\
\mathrm{TWR} & =\text { tool wear rate } \\
S R & =\text { surafce roughness } \\
\mathrm{OA} & =\text { orthogonal array }
\end{aligned}
$$

\section{Stationary USM Set Up}

In USM, high frequency electrical energy is converted into mechanical vibrations via a transducer/booster combination which are then transmitted to an energy focusing as well as amplifying device: horn/tool assembly. This causes the tool to vibrate along its longitudinal axis at high frequency; usually above $20 \mathrm{kHz}$ with amplitude of 12-50 $\mu \mathrm{m}$ (Kennedy et al., 1975; Kremer, 1991). The power ratings range from $50-3000 \mathrm{~W}$ and a controlled static load is applied to the tool. Abrasive slurry, which is a mixture of abrasive material; e.g. silicon carbide, boron carbide or aluminium oxide suspended in water or some suitable carrier medium is continuously pumped across the gap between the tool and work $(\sim 25-60 \mu \mathrm{m})$. The vibration of the tool causes the abrasive particles held in the slurry to impact the work surface leading to material removal by microchipping (Moreland, 1984). Figure 1 shows the basic elements of an USM set up using a megnetostrictive transducer.

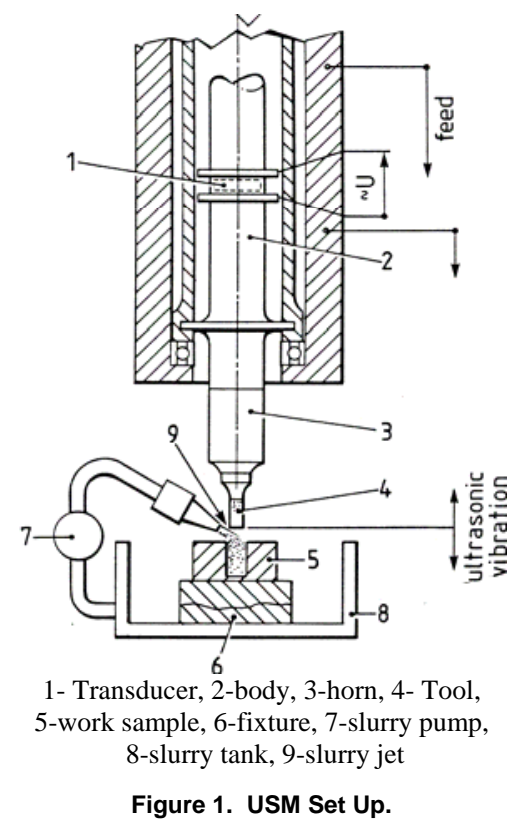

\section{Materials and Methods}

Commercially pure titanium (ASTM Grade-I) has been used as the work material in the present investigation. The chemical composition and other mechanical properties of the material are shown in Table 1. Five type of tools made of high carbon steel, high speed steel, cemented carbide, titanium (ASTM Grade-I) and titanium alloy (ASTM Grade-V) with straight cylindrical geometry (diameter $8 \mathrm{~mm}$ ) were used in this investigation. All the tools except cemented carbide were made as one piece unit and attached to the horn by tightening the threaded portion of the tool with the horn. Tool of cemented carbide was prepared by silver brazing the tip with replaceable threaded part at $1200 \mathrm{~F}$. Three types of abrasive materials were used: silicon carbide, aluminium oxide and boron carbide. Three different grit sizes were selected for each abrasive material: 220, 320 and 500. These levels were selected by means of pilot experimentation performed to study the influence of the parameter grit size on the tool wear rate of different tool materials in ultrasonic drilling of titanium. 
Table 1. Chemical composition and other mechanical properties of titanium (ASTM Grade I and V)

\begin{tabular}{|c|c|c|c|c|c|c|c|c|c|c|c|c|c|}
\hline \multicolumn{7}{|c|}{$\begin{array}{c}\text { Chemical composition (by weight \%) of } \\
\text { Titanium (ASTM Grade-I) }\end{array}$} & \multicolumn{7}{|c|}{$\begin{array}{c}\text { Chemical composition (by weight \%) of } \\
\text { Titanium (ASTM Grade-V) }\end{array}$} \\
\hline $\mathbf{O}$ & $\mathbf{N}$ & $\mathbf{C}$ & $\mathbf{H}$ & $\mathbf{F e}$ & $\mathbf{T i}$ & balance & $\mathbf{O}$ & $\mathbf{N}$ & C & $\mathbf{F e}$ & Al & $\mathbf{V}$ & $\mathbf{T i}$ \\
\hline 0.18 & 0.03 & 0.08 & 0.01 & 0.2 & 99.1 & 0.4 & 0.15 & 0.05 & 0.06 & 0.25 & 5.8 & 4.1 & 89.3 \\
\hline \multicolumn{7}{|c|}{ Yield Strength 220} & \multicolumn{7}{|c|}{ Ultimate strength $910 \mathrm{MPa}$} \\
\hline \multicolumn{3}{|c|}{ Ultimate strength } & \multicolumn{4}{|c|}{$340 \mathrm{MPa}$} & \multicolumn{3}{|c|}{ Hardness } & \multicolumn{4}{|c|}{$187 \mathrm{HV}$} \\
\hline \multirow{2}{*}{\multicolumn{3}{|c|}{$\begin{array}{l}\text { Hardness } \\
\text { Density }\end{array}$}} & \multicolumn{4}{|c|}{$115 \mathrm{HV}$} & \multicolumn{3}{|c|}{ Density } & \multicolumn{4}{|c|}{$4.41 \mathrm{~g} / \mathrm{cm}^{3}$} \\
\hline & & & \multicolumn{4}{|c|}{$4.51 \mathrm{~g} / \mathrm{cm}^{3}$} & \multicolumn{7}{|c|}{ Mod. of elasticity $114 \mathrm{GPa}$} \\
\hline \multicolumn{3}{|c|}{$\begin{array}{l}\text { Density } \\
\text { Mod. of elasticity }\end{array}$} & \multicolumn{4}{|c|}{$103 \mathrm{GPa}$} & \multicolumn{7}{|c|}{ Fracture toughness $68 \mathrm{Mpam}^{1 / 2}$} \\
\hline
\end{tabular}

Table 2. Process parameters and their values at different levels.

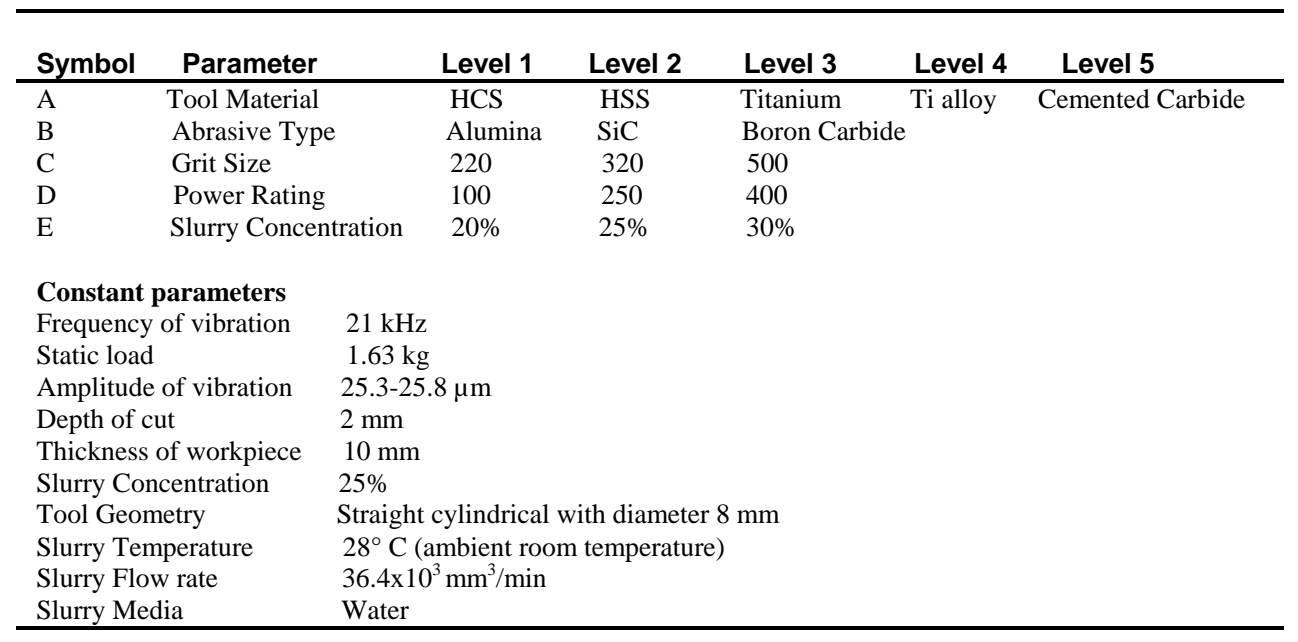

In contrast to the DOE technique, pilot experimentation is typically a one factor at a time approach, whose objective is to study the influence of the parameter under consideration on certain performance characteristic by varying the levels for the parameter on random basis. Power rating of the ultrasonic machine was selected as another process parameter for this investigation. Three levels of power rating were finalized from the pilot experimentation: $100 \mathrm{~W}, 250 \mathrm{~W}$ and $400 \mathrm{~W}$. The process parameters and their levels selected for the final experimentation has been depicted in Table 2.

The experiments were conducted on an 'AP-500 model SonicMill' ultrasonic machine. The complete setup is divided into the four sub systems; power supply, Mill module unit, slurry recirculating system and Workpiece. To measure the tool wear rate (TWR), the time taken for drilling each hole was recorded using stop watch. The tool was weighed before and after drilling each hole using electronic balance. The weight loss for drilling each hole was thus recorded. TWR was calculated by taking the ratio of weight loss of tool per hole to the product of drilling time per hole. The surface roughness of the machined surface was evaluated by using Perthometer (Mahr, M4pi) with a cut off value of $0.25 \mathrm{~mm}$ and tracing length of $1.50 \mathrm{~mm}$. Three observations were taken for each hole and were averaged to obtain the value of roughness.

This paper makes use of Taguchi's method for designing the experiments. Taguchi recommends use of orthogonal arrays for laying out the experiments. The optimum condition is identified by studying the main effects of each of the parameters. The main effects indicate the general trend of influence of each parameter. The knowledge of contribution of individual parameters is a key in deciding the nature of control to be established on a production process. The Analysis of Variance (ANOVA) is the statistical treatment most commonly applied to the results of the experiments in determining the percent contribution of each parameter against a stated level of confidence. The approach to be used for completing the analysis, which Taguchi strongly recommends for multiple runs, is to use Signal-to-Noise $(\mathrm{S} / \mathrm{N})$ ratio. The $\mathrm{S} / \mathrm{N}$ ratio is a concurrent quality metric linked to the loss function (Barker, 1990). By maximizing the $\mathrm{S} / \mathrm{N}$ ratio, the loss associated can be minimized. The $\mathrm{S} / \mathrm{N}$ ratio determines the most robust set of operating conditions from variation within the results.

In the present investigation, both the analysis - the raw data analysis and $\mathrm{S} / \mathrm{N}$ data analysis - have been performed. The effects of the selected USM-process parameters on the selected performance characteristics have been investigated through the plots of the main effects based on raw data. The optimum condition for each of the performance characteristics has been established through $\mathrm{S} / \mathrm{N}$ data analysis aided by the raw data analysis. No outer array has been used instead; experiments have been repeated three times at each experimental condition. The optimal process parameters are verified through a confirmation experiment.

\section{Experimentation and Data Collection}

Before finalizing a particular orthogonal array for the purpose of designing the experiments, the following two things must be established (Ross, 1988):

1. The number of parameters and interactions of interest

2. The number of levels for the parameters of interest

In the present investigation, four different process parameters have been selected as already discussed. The tool material factor has five levels whereas all other parameters such as abrasive type, grit size and power rating of the machine have three levels each. Hence, L18 array (in modified form) was selected for the present investigation. L18 array has a special property that the two way interactions between the various parameters are partially 
confounded with various columns and hence their effect on the assessment of the main effects of the various parameters is minimized. It is not possible to assess the possible two factor interactions in L18 array but the main effects of different process parameters can be assessed with reasonable accuracy. According to the scheme of the experimentation outlined in the L18 OA (Table 3 ), holes were drilled in the work pieces which were prepared in the form of circular discs with thickness of $10 \mathrm{~mm}$ and diameter of 34 $\mathrm{mm}$.

Table 3. Control log for Experimentation based on L-18 OA.

\begin{tabular}{|c|c|c|c|c|}
\hline $\begin{array}{l}\text { Exp. } \\
\text { No. }\end{array}$ & $\begin{array}{l}\text { A: Col. } 1 \\
\text { Tool } \\
\text { Material }\end{array}$ & $\begin{array}{l}\text { B: Col. } 2 \\
\text { Abrasive }\end{array}$ & $\begin{array}{l}\text { C: Col. } 3 \\
\text { Grit Size }\end{array}$ & $\begin{array}{l}\text { D: Col. } 4 \\
\text { Power } \\
\text { Rating } \\
\end{array}$ \\
\hline 1 & HCS & Alumina & 220 & 100 \\
\hline 2 & HCS & $\mathrm{SiC}$ & 320 & 250 \\
\hline 3 & $\mathrm{HCS}$ & $\mathrm{B}_{4} \mathrm{C}$ & 500 & 400 \\
\hline 4 & HSS & Alumina & 220 & 250 \\
\hline 5 & HSS & $\mathrm{SiC}$ & 320 & 400 \\
\hline 6 & HSS & $\mathrm{B}_{4} \mathrm{C}$ & 500 & 100 \\
\hline 7 & Titanium & Alumina & 320 & 100 \\
\hline 8 & Titanium & $\mathrm{SiC}$ & 500 & 250 \\
\hline 9 & Titanium & $\mathrm{B}_{4} \mathrm{C}$ & 220 & 400 \\
\hline 10 & Ti alloy & Alumina & 500 & 400 \\
\hline 11 & Ti alloy & $\mathrm{SiC}$ & 220 & 100 \\
\hline 12 & Ti alloy & $\mathrm{B}_{4} \mathrm{C}$ & 320 & 250 \\
\hline 13 & Carbide & Alumina & 320 & 400 \\
\hline 14 & Carbide & $\mathrm{SiC}$ & 500 & 100 \\
\hline 15 & Carbide & $\mathrm{B}_{4} \mathrm{C}$ & 220 & 250 \\
\hline 16 & $\mathrm{HCS}$ & Alumina & 500 & 250 \\
\hline 17 & HCS & $\mathrm{SiC}$ & 220 & 400 \\
\hline 18 & $\mathrm{HCS}$ & $\mathrm{B}_{4} \mathrm{C}$ & 320 & 100 \\
\hline
\end{tabular}

Each trial was replicated twice, hence, three holes were drilled for each of the eighteen trial runs and moreover, all the fifty four trial runs in all were executed in completely randomized fashion to reduce the effect of experimental noise to the maximum possible extent. The flow rate of the abrasive slurry was maintained constant at a value of $36.4 \times 10^{3} \mathrm{~mm}^{3} / \mathrm{min}$. To avoid any possibility of dullness of the edges of the abrasive grains, a large volume of slurry was prepared. The experimental results are summarized in Table 4 and Table 5 for tool wear rate and surface roughness as the response variable respectively.

\section{Analysis of Data}

\section{Evaluation of $\mathrm{S} / \mathrm{N}$ ratio and Main Effects}

The $\mathrm{S} / \mathrm{N}$ ratio is obtained using Taguchi's methodology. Here, the term 'signal' represents the desirable value (mean) and the 'noise' represents the undesirable value (standard deviation). Thus, the $\mathrm{S} / \mathrm{N}$ ratio represents the amount of variation present in the performance characteristic. Depending upon the objective of the performance characteristic, there can be various types of $\mathrm{S} / \mathrm{N}$ ratios. Here, the desirable objective is lower values of tool wear rate as well as surface roughness. Hence, the Lower-the-Better (LB) type $\mathrm{S} / \mathrm{N}$ ratio, as defined below was applied for transforming the raw data.
Table 4. Experimental Results of TWR.

\begin{tabular}{|c|c|c|c|c|c|}
\hline \multirow{2}{*}{$\begin{array}{l}\text { Exp. } \\
\text { No. }\end{array}$} & \multicolumn{3}{|c|}{ TWR (mg/min) } & \multirow{2}{*}{$\begin{array}{c}\text { Avg. } \\
\text { TWR } \\
\text { (mg/min) }\end{array}$} & \multirow{2}{*}{$\begin{array}{r}\text { S/N } \\
\text { Ratio } \\
\text { (dB) }\end{array}$} \\
\hline & R1 & R2 & R3 & & \\
\hline 1 & 3.87 & 4.13 & 3.56 & 3.85 & 11.73 \\
\hline 2 & 4.85 & 5.28 & 4.57 & 4.90 & 14.13 \\
\hline 3 & 6.56 & 6.30 & 7.00 & 6.62 & 16.43 \\
\hline 4 & 3.20 & 3.00 & 3.36 & 3.19 & 10.08 \\
\hline 5 & 8.16 & 8.08 & 8.25 & 8.16 & 18.24 \\
\hline 6 & 1.88 & 1.64 & 1.97 & 1.83 & 5.27 \\
\hline 7 & 0.57 & 1.33 & 0.54 & 0.81 & 0.23 \\
\hline 8 & 1.40 & 1.89 & 1.21 & 1.50 & 3.68 \\
\hline 9 & 6.00 & 6.50 & 5.77 & 6.09 & 15.70 \\
\hline 10 & 0.95 & 0.62 & 0.87 & 0.81 & 1.67 \\
\hline 11 & 0.72 & 0.72 & 0.56 & 0.67 & 3.47 \\
\hline 12 & 1.86 & 1.95 & 1.78 & 1.86 & 5.25 \\
\hline 13 & 7.75 & 7.95 & 8.26 & 7.99 & 18.05 \\
\hline 14 & 5.12 & 5.06 & 5.50 & 5.23 & 14.37 \\
\hline 15 & 9.37 & 9.88 & 9.10 & 9.45 & 19.51 \\
\hline 16 & 1.45 & 1.70 & 1.40 & 1.52 & 3.65 \\
\hline 17 & 12.30 & 12.00 & 12.36 & 12.22 & 21.74 \\
\hline 18 & 3.23 & 2.47 & 4.00 & 3.23 & 10.35 \\
\hline
\end{tabular}

Table 5. Experimental Results of Surface Roughness.

\begin{tabular}{|c|c|c|c|c|c|}
\hline \multirow{2}{*}{$\begin{array}{l}\text { Exp. } \\
\text { No. }\end{array}$} & \multicolumn{3}{|c|}{ SR (microns) } & \multirow{2}{*}{$\begin{array}{c}\text { Avg. SR } \\
\text { (microns) }\end{array}$} & \multirow{2}{*}{$\begin{array}{r}\text { S/N } \\
\text { Ratio } \\
\text { (dB) } \\
\end{array}$} \\
\hline & R1 & R2 & R3 & & \\
\hline 1 & 0.85 & 0.98 & 0.92 & 0.91 & 0.74 \\
\hline 2 & 1.24 & 1.18 & 1.05 & 1.16 & -1.28 \\
\hline 3 & 0.73 & 0.70 & 0.52 & 0.65 & 3.65 \\
\hline 4 & 1.17 & 1.11 & 0.82 & 1.03 & -0.37 \\
\hline 5 & 1.20 & 1.19 & 1.32 & 1.24 & -1.85 \\
\hline 6 & 0.53 & 0.64 & 0.60 & 0.59 & 4.55 \\
\hline 7 & 0.68 & 0.50 & 0.72 & 0.63 & 3.86 \\
\hline 8 & 0.73 & 0.89 & 0.90 & 0.84 & 1.47 \\
\hline 9 & 2.14 & 2.20 & 1.90 & 2.08 & -6.37 \\
\hline 10 & 0.56 & 0.68 & 0.75 & 0.66 & 3.50 \\
\hline 11 & 0.60 & 0.79 & 0.64 & 0.67 & 3.32 \\
\hline 12 & 0.85 & 0.86 & 0.81 & 0.84 & 1.51 \\
\hline 13 & 1.04 & 1.12 & 0.97 & 1.04 & -0.38 \\
\hline 14 & 0.75 & 0.65 & 0.60 & 0.67 & 3.48 \\
\hline 15 & 1.82 & 1.68 & 1.70 & 1.75 & -4.78 \\
\hline 16 & 0.77 & 0.83 & 0.66 & 0.75 & 2.42 \\
\hline 17 & 2.18 & 2.29 & 2.26 & 2.23 & -7.01 \\
\hline 18 & 0.73 & 0.74 & 0.92 & 0.80 & 1.92 \\
\hline
\end{tabular}

$$
\eta=-10 \log \left\{\frac{1}{n} \cdot \sum_{1}^{n} y_{i}^{2}\right\}
$$

Where $y_{j}$ is the value of the characteristic in an observation $j$ and $n$ is the number of observations or number of repetitions in a trial.

The main effects can be studied by the level average response analysis of raw data or of $\mathrm{S} / \mathrm{N}$ data. The analysis is done by averaging the raw and/or $\mathrm{S} / \mathrm{N}$ data at each level of each parameter and plotting the values in graphical form. The level average 
responses from the raw data help in analyzing the trend of the performance characteristic with respect to the variation of the factor under study. The level average response plots based on the $\mathrm{S} / \mathrm{N}$ data help in optimizing the objective function under consideration. The peak points of these plots correspond to the optimum condition. The main effects of raw data and those of the $\mathrm{S} / \mathrm{N}$ ratio are shown in Fig. 2 (tool wear rate) and Fig. 3 (surface roughness).
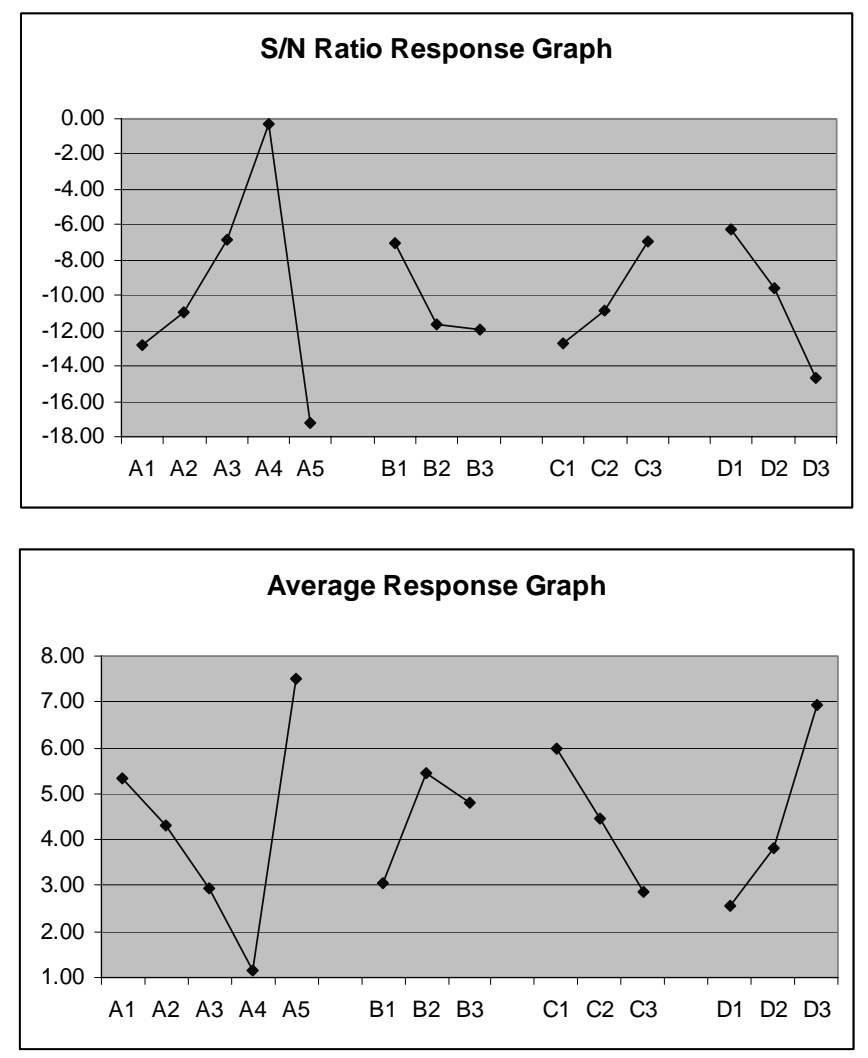

Figure 2. Effects of process parameters on TWR-raw data and S/N.

\section{Analysis of Variance (ANOVA)}

The percentage contribution of various process parameters on the selected performance characteristic can be estimated by performing ANOVA. Thus, information about how significant the effect of each controlled parameter is on the quality characteristic of interest can be obtained. The total variation in the result is the sum of variation due to various controlled factors and their interactions and variation due to experimental error. The ANOVA for raw data and $\mathrm{S} / \mathrm{N}$ data have been performed to identify the significant parameters and to quantify their effect on the performance characteristic. The ANOVA based on the raw data signifies the factors, which affect the average response rather than reducing variation. But ANOVA based on $\mathrm{S} / \mathrm{N}$ ratio takes into account both these aspects and hence it is used here. The pooled ANOVA S/N data are given in Table 6 (TWR) and Table 7 (surface roughness).

The percentage contributions of significant process parameters on material removal rate for raw and $\mathrm{S} / \mathrm{N}$ data are shown in Figures 4, 5 respectively. The most favorable conditions or optimal levels of process parameters have been established by analyzing response curves of $\mathrm{S} / \mathrm{N}$ ratio associated with the raw data.

After determination of the optimum condition, the mean of the response at the optimum condition is computed. This value is calculated by considering only the significant factors that are concluded by ANOVA. It may also happen that the predicted combination of the parameters be identical to one of the trial combinations executed already during the final experimentation stage. Under such situations, the most direct way to estimate the mean of that treatment combination is to average out all the results for the trials that are set at that particular levels (Ross, 1988).

\section{Results and Discussions}

\section{Tool Wear Rate}

It can be observed from Figure 2 that the tool material affects the rate of wear of the tool very significantly. Moreover, the different tool materials used in the experimentation can be ranked in the order of increasing tool wear rate as Ti alloy, Titanium, HSS, HCS, Cemented carbide. The lowest tool wear has been recorded for titanium alloy (ASTM Grade -V). This can be attributed to its excellent combination of high fracture toughness and optimum hardness (42 RC) from the point of view of USM process. Also the work hardening ability of this material has been found to be superior as compared to other materials used in this research. Hence, as a result of the repeated impacts of abrasive particles on the tool surface, it goes under significant amount of plastic deformation before fracture. On the other hand, Cemented carbide being much harder (92 RC) and brittle is worn out at a very rapid rate as a result of the brittle fracture of the tool surface. It can also be concluded that the tool wear rate increases with the increase in relative brittleness of the tool work combination, which has also been suggested by many other researchers (Komaraiah and Reddy, 1993; Moreland, 1988).

The type of abrasive used also puts a significant effect on tool wear rate for the different tool materials. It has been observed that use of Silicon carbide as abrasive results in more tool wear rate as compared to that achieved with the use of alumina. This can be explained on the basis of the relative knoop hardness of the abrasive grains. Silicon carbide is also having $50-60 \%$ more cutting power as compared to alumina. Hence, it promotes the increase in tool wear rate. However, use of boron carbide as the abrasive has lead to a lesser TWR as compared to silicon carbide. This gives rise to the possibility of the abrasive-tool interaction playing a role in this phenomenon.

The use of a coarser grit size promotes the increase in tool wear rate further (Fig. 2) Use of coarse abrasive grains results in stronger impacts on the tool surface and hence the rate of fracture increases. It has also been observed that for a given tool material, TWR is maximum at that particular grit size-power level combination which corresponds to maximum MRR. In other words, TWR is maximum at the points of maximum MRR. This phenomenon has also been put forward by other investigators (Jadoun et al., 2006; Smith, 1973). In USM process, the parameter settings that result in maximum MRR also involve maximum TWR. This is the inherent characteristic of the process.

The tool wear rate (TWR) has been found to be increasing with a corresponding increase in power rating of the ultrasonic machine, the rate of increase being sluggish while the power rating is increased from $100 \mathrm{~W}$ to $250 \mathrm{~W}$. But with an increase in the power rating from $250 \mathrm{~W}$ to $400 \mathrm{~W}$ brings a sharp increment in TWR. This can be attributed to the tremendous increment in the momentum with which the abrasive particles strike with the work surface as well as the tool surface while the power rating is increased from 250 $\mathrm{W}$ to $400 \mathrm{~W}$. The particles striking with more energy cause rapid fracturing of the tool surface thus promoting TWR. 


\section{Surface Roughness}

It can be observed from Figure 3 that the tool material affects the surface quality obtained significantly. Moreover, the different tool materials used in the experimentation can be ranked in the order of increasing surface roughness as Ti alloy, HSS, HCS, Titanium, Cemented Carbide. The lowest tool wear has been recorded for titanium alloy (ASTM Grade $-\mathrm{V}$ ). This can be explained on the basis of the Machining rate obtained with different tool materials. In USM process, as the machining rate increases, the surface quality deteriorates, the reason being formation of larger micro cavities at the time of machining. The larger micro cavities give rise to rougher surface. As the use of titanium alloy tool involves least machining rate, it also promotes the reduction in surface roughness, thereby generating better surface finish.
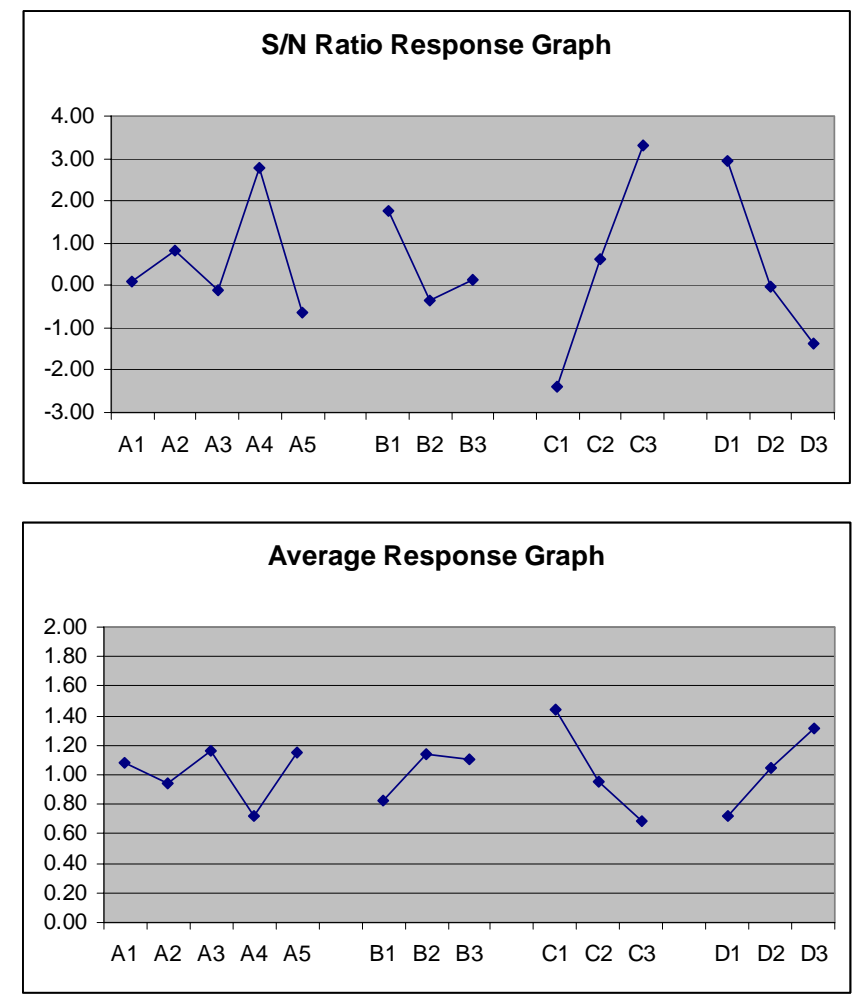

Figure 3. Effects of process parameters on SR-raw data and S/N ratio.

The use of a coarser grit size promotes the increase in surface roughness, thus deteriorating the surface quality (Figure 1). Use of coarse abrasive grains results in stronger impacts on the tool surface and hence the rate of fracture increases. It has also been observed that for a given tool material, surface roughness is maximum at that particular grit size-power level combination which corresponds to maximum MRR. In other words, surface roughness is maximum at the points of maximum MRR. This is the inherent characteristic of the process, as explained earlier.

The surface roughness of the machined surface has been found to be increasing with a corresponding increase in power rating of the ultrasonic machine, the rate of increase being sluggish while the power rating is increased from $100 \mathrm{~W}$ to $250 \mathrm{~W}$. But with an increase in the power rating from $250 \mathrm{~W}$ to $400 \mathrm{~W}$ brings a sharp increment in SR. This can be attributed to the tremendous increment in the momentum with which the abrasive particles strike with the work surface as well as the tool surface while the power rating is increased from $250 \mathrm{~W}$ to $400 \mathrm{~W}$. The particles striking with more energy cause rapid fracturing of the tool surface thus promoting surface roughness as well.

\section{Selection of Optimum Settings}

In the present investigation, both the response variables are "Lower the Better" type characteristics. Therefore, lower values of TWR as well as surface roughness are considered to be optimal. It is clear from Figure 2 that tool wear rate (TWR) is lowest at the fourth level of tool material parameter $\left(\mathrm{A}_{4}\right)$, first level of abrasive material parameter (B1), third level of the grit size (C3) and also the first level of power rating (D1). The main effects of the $\mathrm{S} / \mathrm{N}$ ratio are also highest at these levels of the parameters that result in lowest tool wear rate. Whereas, Surface Roughness (SR) is lowest at the fourth level of tool material parameter $\left(\mathrm{A}_{4}\right)$, first level of abrasive material parameter (B1), third level of the grit size (C3) and also the first level of power rating (D1).

To establish the relative significance of the individual factors, ANOVA has been performed, both on raw data and $\mathrm{S} / \mathrm{N}$ data. Because of the ability of $\mathrm{S} / \mathrm{N}$ data to reflect both the average effects and the variation in the results, ANOVA results based on $\mathrm{S} / \mathrm{N}$ data are depicted here in Tables 6,7 . With regarding to the $\mathrm{S} / \mathrm{N}$ data, the ANOVA test summary (Table 6) indicates the same results as obtained by using the raw data. Tool factor emerges as the most significant (with a p value 0.001) followed by power rating. Abrasive material and grit size are almost equally significant as both assume the same $\mathrm{p}$ value. Tool factor contributes for 53.77 percent in the variation of TWR whilst contribution of abrasive factor is almost nil. Power rating emerges as another highly significant factor, with a percent contribution of 21.67 in the variation of TWR. The grit size factor is also marginally significant at $95 \%$ confidence level, with a percent contribution of 9.51 .

As far as surface roughness is concerned, grit Size emerges as the most significant (with a p value 0.003 ) with 44.25 percent contribution to the variation of surface quality followed by power rating factor ( $p$ value 0.010 , Table 7 ). Tool material and abrasive material are almost equally insignificant as both assume the same $\mathrm{p}$ value. Tool factor contributes for only 10.51 percent in the variation of SR whilst contribution of abrasive factor is almost negligible. Statistically, it can be said that except grit size and power rating factors, no other factor can be termed as significant at a confidence level of $95 \%$.

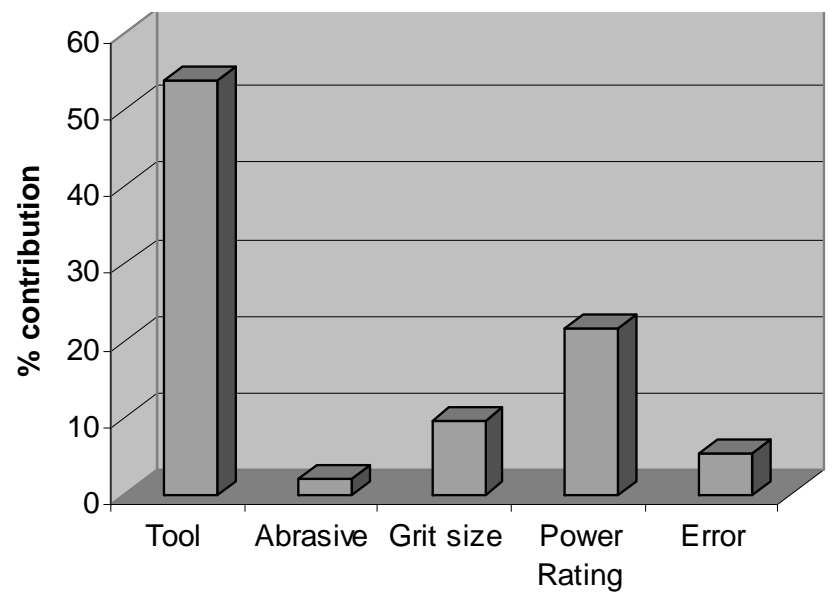

Figure 4. Percent contributions for TWR (S/N Data). 
Table 6.ANOVA results for TWR (S/N Ratio).

\begin{tabular}{lccccccc}
\hline & & & & & & & \\
Source & DF & Seq. SS & Adj. SS & Adj. MS & F & P & (\%) \\
\hline Tool & 4 & 556.296 & 556.295 & 139.04 & 17.47 & 0.001 & $\mathbf{5 3 . 7 7}$ \\
Abrasive & 2 & 99.412 & 19.412 & 49.706 & 6.23 & 0.028 & $\mathbf{1 . 8 7}$ \\
Grit Size & 2 & 98.43 & 98.43 & 49.22 & 6.17 & 0.029 & $\mathbf{9 . 5 1}$ \\
Power Rating & 2 & 223.68 & 223.68 & 111.84 & 14.01 & 0.004 & $\mathbf{2 1 . 6 7}$ \\
Error & 7 & 55.843 & 55.843 & 7.98 & & & $\mathbf{5 . 4 2}$ \\
Total & 17 & 1033.59 & & & & & \\
\hline
\end{tabular}

Table 7 ANOVA results for Surface Roughness (S/N Ratio)

\begin{tabular}{lccccccc}
\hline Source & DF & Seq. SS & Adj. SS & Adj. MS & F & P & (\%P) \\
\hline Tool & 4 & 22.436 & 22.436 & 5.604 & 1.75 & 0.244 & $\mathbf{1 0 . 5 1}$ \\
Abrasive & 2 & 12.637 & 12.637 & 6.318 & 1.97 & 0.210 & $\mathbf{5 . 9 2}$ \\
Grit Size & 2 & 94.262 & 94.262 & 47.131 & 14.7 & 0.003 & $\mathbf{4 4 . 2 5}$ \\
Power Rating & 2 & 61.684 & 61.684 & 30.84 & 9.60 & 0.010 & $\mathbf{2 8 . 9 5}$ \\
Error & 7 & 22.486 & 22.486 & 3.212 & & & $\mathbf{1 0 . 5 3}$ \\
Total & 17 & 213.489 & & & & & \\
\hline
\end{tabular}

The Taguchi approach for predicting the mean performance characteristics and determination of confidence intervals for the predicted mean has been applied. Three confirmation experiments for each performance characteristics have been performed at optimal settings of the process parameters and the average value has been reported in next section. The average values of the performance characteristics obtained through the confirmation experiments (three runs) must be within the 95\% confidence interval, $\mathrm{CI}_{\mathrm{CE}}$ (fixed number of confirmation experiments). However, the average values of the performance characteristics obtained from the confirmation experiments may or may not lie within the $95 \%$ confidence interval, $\mathrm{CI}_{\mathrm{POP}}$ (mean of the population).

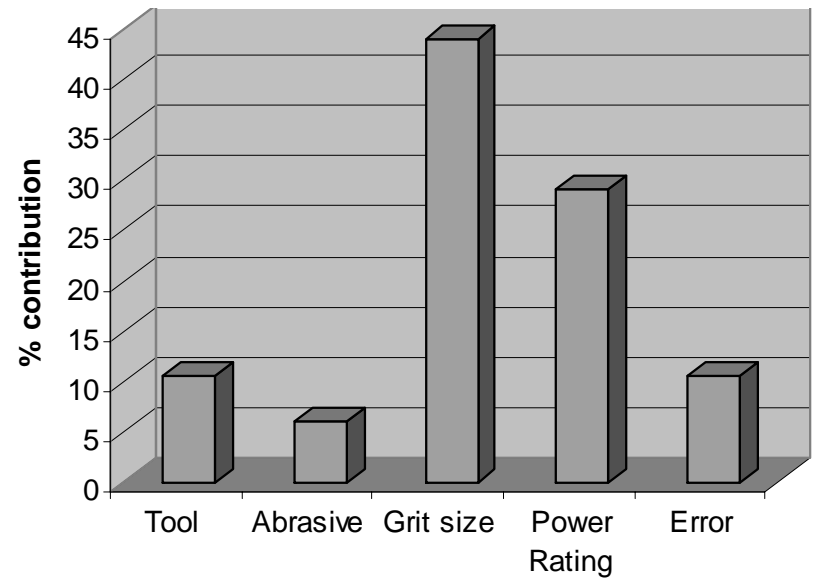

Figure 5. Percent contributions for SR (S/N Data).

For tool wear rate, the overall mean of the population is $\mu=3.83$

The predicted optimum value of TWR is calculated as, $\mu_{\mathrm{TWR}}=(\mu \mathrm{A} 4+\mu \mathrm{B} 1+\mu \mathrm{C} 3+\mu \mathrm{D} 1)-(3 \mu)=0.45$

The $95 \%$ confidence levels for the mean of the population and three confirmation experiments have been calculated as:

$\mathrm{CI}_{\mathrm{POP}}=0.39<\mu_{\mathrm{TWR}}<0.54$
$\mathrm{CI}_{\mathrm{CE}}=0.33<\mu_{\mathrm{TWR}}<0.60$

For Surface Roughness

The overall mean of the population is $\mu=1.02$

The predicted optimum value of SR is calculated as,

$\mu_{\mathrm{SR}}=(\mu \mathrm{C} 3+\mu \mathrm{D} 1)-\mu=0.38$

$\mathrm{CI}_{\mathrm{POP}}=0.35<\mu_{\mathrm{SR}}<0.50$

$\mathrm{CI}_{\mathrm{CE}}=0.28<\mu_{\mathrm{SR}}<0.58$

\section{Confirmation Experiments}

Three experiments were conducted at the optimum settings of the process parameters. The mean value of TWR from these experiments was found to be 0.49 , which is well contained by the confidence intervals (in fact both $\mathrm{CI}_{\mathrm{POP}}, \mathrm{CI}_{\mathrm{CE}}$ contain this value) of optimum TWR. For surface roughness, a mean value equal to 0.41 was obtained, again satisfying both the confidence intervals. This validates the optimization results obtained from the Taguchi method.

\section{Conclusions}

This work shows optimization of process parameters in ultrasonic machining of pure titanium (ASTM Grade-I) using the Taguchi method. The individual factors Viz. tool material, abrasive material, slurry grit size and power rating have significant effect on TWR. The tool materials undertaken in the study can be ranked in increasing order of their performance (in terms of decreasing TWR) as: Cemented Carbide, HCS, HSS, Titanium, Titanium alloy. Tool wear rate has been found to be increasing linearly with a corresponding increase in the grit size of the abrasive slurry used. Use of higher power rating leads to more TWR. The quality of machined surface depends primarily on grit size of the abrasive used and power rating of the ultrasonic machine. The optimum process conditions for both the response variables (TWR, surface roughness) have been found to be as following:

- Titanium alloy (ASTM Grade-V) as tool material

- Alumina (brown) as abrasive slurry

- Slurry grit size $=500$ 
- $\quad$ Power Rating $=100 \mathrm{~W}(20 \%)$

It can be observed that the process settings that correspond to optimum tool wear rate also result in optimum surface quality. Hence, it can be concluded that in ultrasonic drilling of pure titanium, tool wear rate and surface quality obtained are highly inter-related; optimization of one also contributes strongly in optimization of the other as well. From the confirmation experiments, the optimum values of tool wear rate and surface roughness were recorded as $0.49 \mathrm{mg} / \mathrm{min}$ and $0.41 \mu \mathrm{m}$ respectively.

\section{Acknowledgements}

The authors would like to thank Mr. K. Ramesh (General Manager, Mishra Dhatu Nigam Limited, Hyderabad) for providing the materials for this research work. The authors are thankful to Mr. Trilok Singh and Mr. Sukhdev Singh (Lab superintendents, Thapar University, Patiala) for providing laboratory facilities. The authors are also thankful to Mr. Charlie White (Sonic-Mill, Albuquerque, NM) for providing technical advice and support.

\section{References}

Aspinwall, D.K. and Kasuga, V., 2001, "The use of ultrasonic machining for the production of holes in Y-TIAL”, Proceedings of the 13th International Symposium for Electro machining ISEM XIII, Vol. 2, Spain, pp. 925-937.

Barker, T.B., 1990, Engineering Quality by Design: Interpreting the Taguchi approach, New York, Marcel-Dekker, Inc., pp. 78-82.

Bendell JD, Disney J, Pridmore WA, 1989, Taguchi methods: applications in world industry. IFS Publications, Bedford, pp. 38-45.

Benedict Gary F.; 1987, Non traditional manufacturing processes, Marcel Dekker, Inc., pp. 67-86.
Ezugwu, E.O and Wang, Z.M., 1997, “Titanium alloys and their machinability-a review”, Journal of Materials Processing Technology, Vol. 68, pp. 262-274.

Hartung, P.D. and Kramer, B.M., 1982, "Tool wear in Titanium Machining”, Annals of CIRP, Vol. 31, p 75.

Hong SY, Markus I, Jeong W, 2001, "New cooling approach and tool life improvement in cryogenic machining of titanium alloy Ti-6Al-4V”, Int. Journal of Machine Tools Manufacture, Vol. 41, pp. 2245-2260.

Jadoun, R.S. et al, 2006, "Manufacturing process optimization for tool wear rate in ultrasonic drilling of engineering ceramics using the Taguchi method”, International Journal of Machining and Machinability of Materials, Vol. 1, pp. 94-114.

Kennedy DK, Grieve RG, 1975, "Ultrasonic machining - a review”, Prod Engineer, Vol.54, pp. 481.

Komaraiah, M. and Reddy, P.N., 1993, "Relative performance of tool materials in ultrasonic machining”, Wear, Vol. 161, No.1/2, pp. 1-10.

Kremer D, Saleh SM, Ghabrial SR, Moisan A, 1981, “The state of art of ultrasonic machining”, Annals of CIRP, STC-E, pp 236-243.

Li. et al, 2005, "Rotary ultrasonic machining of ceramic matrix composites-feasibility study and designed experiments", International Journal of Machine Tools and Manufacture, pp. 1-10.

Moreland, M.A., 1988, "Versatile performance of Ultrasonic machining”, Ceramic Bulletin, Vol. 67, No.6, pp. 1045-1047

Ross, P.J., 1988, Taguchi Technique for Quality Engineering, McGrawHill book company, New York.

Smith, T.J., 1973, "Parameter influences in ultrasonic machining", Abrasives, Vol. 11, No. 5, pp. 196-198.

Takeyama, H. and Murata, R., 1962, "Study on Machinability of Pure Titanium”, Journal of JSPE, Vol. 28, No. 6, pp. 331.

Thoe T.B., Aspinwall D.K. and Wise M.L.H., 1998, "Review on Ultrasonic Machining”, International Journal of Machine Tools Manufacture, Vol.38, No.4, pp 239-255.

Titanium: A Technical Guide, 1988, ASM International, Materials Park, $\mathrm{OH}$, page 75-85.

Wood, R.A. and Favor, R.J., 1972, Titanium alloys Handbook, Air Force Materials Laboratory, Ohio, 45433, pp. 45-46. 